\title{
New Aspects of Voice Physiology
}

\section{VOCAL FOLD VIBRATIONS WITHOUT AIR-STREAM IN A LIVING HUMAN BEING}

\author{
By G. H. BRECKWOLDT, Ph. D.
}

JOHANNES MÜLLER (1801-1858) had shown the medical world that there were certain laws of voice-production which could be demonstrated in experiments with the larynges of corpses. In these experiments he showed that (1) the pitch of the tone thus artificially produced depended on the tension of the vocal folds. In other words, if the air-stream remained constant and the tension of the folds of the same larynx was increased, the pitch of the tone went up. He found that (2) with an increasing intensity of the air-stream the volume of the tone increased and the pitch went up. If, however, (3) the pitch of the tone was to remain constant but its volume to increase, the air-stream must be increased but the tension of the vocal folds must be decreased. MÜLLER regulated the tension of the folds with weights. The air pressure was produced by means of bellows (cf. H. GUTZMANN, "Sprachheilkunde" Berlin, 1924, p.14 seq.)

Scientists who held against MÜLLER'S EXPERIMENT the fact that he had gained his results from experiments with the heads of bodies and not with living individuals, were directed to experiments demonstrating subglottal pressure "in vivo" i.e. in patients who, after tracheotomy had to wear a cannula. These experiments were supposed to show, similar to MÚLLER'S findings, that voice pitch depends upon the interaction of vocal fold tension and air-pressure. (cf. CAGNIARD DE LA TOUR 1857). The general idea was that the breath-stream activated, i.e. vibrated the otherwise passive vocal folds.

As early as 1898 EWALD and after him NAGEL, in 1906.07, criticised the theory that the vocal cords vibrate through the air-stream only; they thought that the air-stream caused the muscles within the folds to vibrate on their own. (cf, G. PANCON. CELLI.CALZIA, "Die Stinmatnung" Leipzig, 1956 p.64). CALZIA says that their criticism was justified, but that their explanation was wrong.

Before R. HUSSON began his experiments in Voice Physiology there were no experiments in this field of any importance. (for the following: cf. $\mathrm{R}$. HUSSON: "Physiology of the Vibrations of the Vocal Folds," Logopaedie en Phoniatrie, Rotterdam, October 1956, and HUSSON'S numerous publications). Up to HUSSON'S researches we find the conventional idea that the larynx can be compared with various musical instruments, such as a horn, a cushion-whistle or organ-pipe, etc.

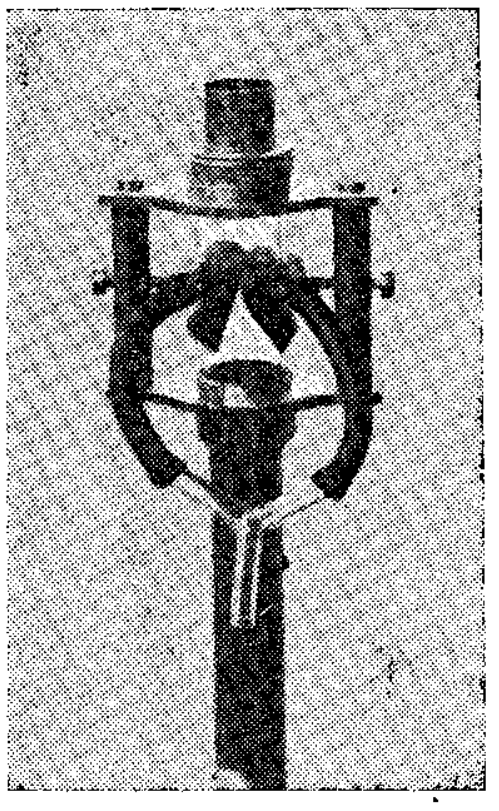

Fig. 1.

CUSHION-WHISTIE by WETHLO. (G. PANCONCELLI-CAIZIA: DIE EXPERIMENTELLE PHONETIK, Berlin 1924, p.39).

In order to put an end to this state of affairs, since 1950 experimental investigations have been undertaken by the "Laboratoire de Physiologie" of the Sorbonne in co-operation with the directors of a great number of Paris hospitals.

\section{THE ACTION POTENTIALS OF THE N. RECURRENS IN PHONATION}

The action potentials of the N. recurrens, which should determine the voice production have been obtained by experiments "in vivo" (in cases which had to undergo laryngectomy) in the Hôpital Boulincourt, Paris, by ANDRE MOULONGUET (1953).

After a year's work, in 1956, MOULONGUET was successful in making photographs and sound recordings. These recordings show that a congruity exists between the rhythm of the action potentials of the $\mathrm{N}$. recurrens and the rhythm of the contractions of the motor units in the musculus vocalis. 


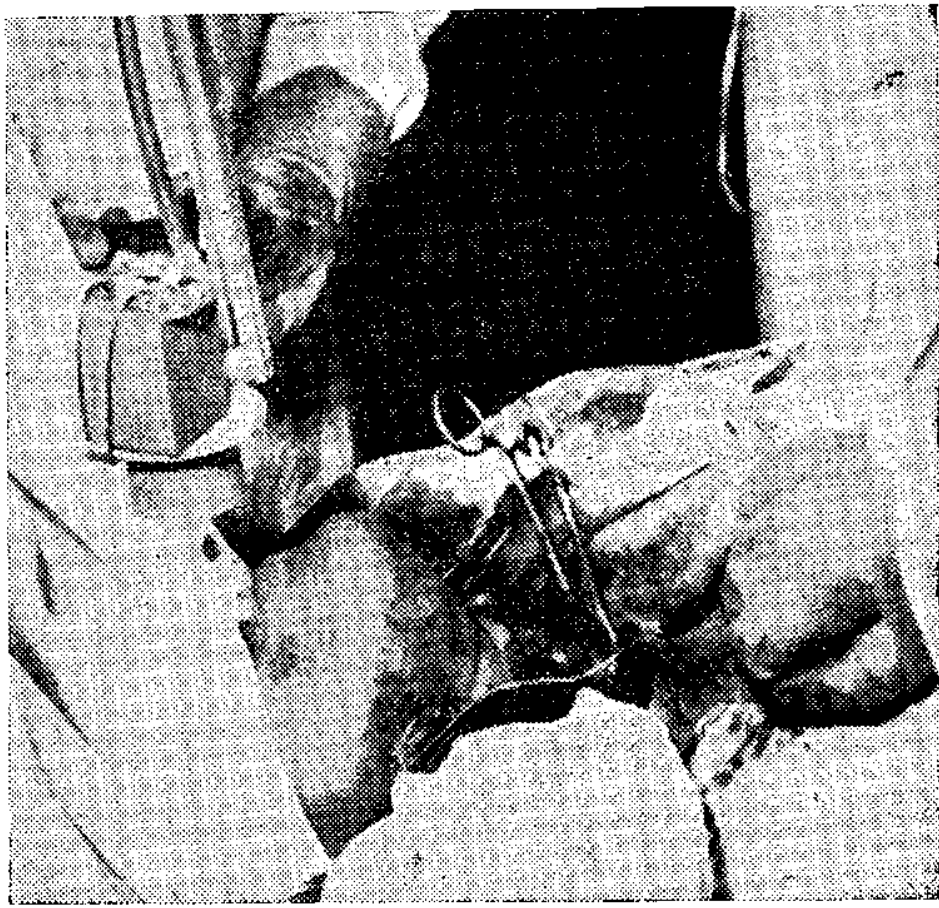

\section{ELECTROMYOGRAPHY OF THE VOCAL FOLDS}

Electromyography of the vocal folds was also performed on human beings "in vivo." The subjects had undergone either an extirpation of the root of the tongue or a hemilaryngectomy. The vocal folds were visible and directly approachable at several points.

In June and December, 1954, electromyographs were made without voice. Herefrom one can conclude:

1. that the vocal folds are the seat of a strong electrical activity, which is minimal during inspiration and maximal in expiration.

2. that the contraction periods of a motor unit of the vocal folds are extremely short, from $0.0008^{\prime \prime}-0.0009^{\prime \prime}$. This is the quickest movement that has been found up to date in the mus. culature of man.

In May, 1955, an exceptionally important finding was made. A patient managed with only his larynx - there was no connection with the bucco-pharyngeal cavity - to produce small scales of 6.7 tones. One could then make a myograph during the voice utterance, and film and sound-recordings were made.

It appeared that ...

1. during the utterance the motor unit of the vocal folds synchronised itself with the fundamental
Fig. 2.

Recurding of the Action Potentials of the recurrent nerve in a human being and "in vivo." Final stage in MOULoNGUET's experiment (Paris, 1953).

The electrodes are placed on the recurrent nerve of the locally anaesthetised patient. and the microphone is put in front of the patient's mouth The surgeon closes the papents of the tracheal cannula with his finger and asks the patient to utter any one sound and hold it for some time.

(A. MOULONGUET, P. LAGET, R. HUSSON:. "Démonstration chez l'homme, de l'existence . "Bulletin de l'Académle Nationale de Medicine, p.475). tone, i.e. with the frequency of the impulses imparted on the folds by the $\mathrm{N}$. recurrens.

2. every crest in the electromyograph is formed by the simultaneous contraction of the group of motor units that are nearest to the electrode.

Precautions were taken so that no microphonic distortion was possible.

\section{DIRECT STIMULATION OF THE N. RECURRENS}

Direct electrical stimulation of the $N$. recurrens was first performed on a dog, in 1951-1952, under general anaesthetic. Experiments were carried out in the Physiological Laboratories of the Sorbonne by PAUL LAGET.

The stimulation took place with frequencies vary. ing from $100-700 \mathrm{~Hz}$. No air passed through the glottis. Observation with the stroboscope showed that ...

1. between $100-500 \mathrm{~Hz}$ the vocal folds vibrated with slight amplitude but with the same frequency as the stimulation. The vibration is maximal between 150 and $200 \mathrm{~Hz}$ : from 300 $\mathrm{Hz}$ onwards it is very small, but it increases with the intensity of the stimulation.

2. about $500 \mathrm{~Hz}$ the vibration only appears at minimal stimulation. 
On another occasion the $N$. recurrens was stimulated with frequencies of $100-700 \mathrm{~Hz}$. The electrical activity of the vocal folds was homorhythmical in every instant.

\section{VOCAL FOLD VIBRATIONS WITHOUT AIR-STREAM IN A LIVING HUMAN BEING}

Until February, 1956, the experiments by LAGET on dogs, which were described just now, were the only ones in which vocal fold vibrations were ex. perimentally created in which there was no occur. rence of air stream through the glottis. This effect was achieved by motor recurrens impulses which went out to the larynx muscles.

On the lst February, 1956, JEAN PIQUET, G. DELACROIX and C. LIBERSA, succeeded in filming vocal cord vibrations of a living human being, through whose glottis there passed no air-stream. The $N$. recurrens was not electrically stimulated, but it was the patient himself who produced the vibrations. In the following I am giving a brief report of this experiment as it is recorded in the publication of the Académie Des Sciences of Paris, dated 27th February, 1956.

Whenever possible, experimental control is used on a human being during an operation. This idea, which LERICHE had, we have applied in order to examine the role of the subglottal pressure in the creating of vocal fold vibrations in the case of a horizontal supraglottal laryngectomy. Thanks to this method, one gets an excellent view of the glottis through the pharyngeal opening. One vocal fold is completely mobile, the other is fixed in a paramedian position. One lets the patient utter a sound (vowel $[a:]$ ); one studies frequency and intensity, one films the event with an ultra-rapid camera in colour.

Later on one opens the trachea and introduces a small probe through the opening. This probe is fitted with a tiny rubber balloon which prevents air escape and is joined to a water-manometer. One lets the patient produce the vowel $[a:]$, while one measures frequency and intensity. One records the pressure as given by the manometer, and the sound is recorded by means of a magnetophone. This has been done on various occasions. The vibrations of the vocal folds have been recorded on a film with a rapid camera. One call then state the following facts:

1. The intensity of a sound stands in direct relationship to the subglottal pressure.
2. The subglottal pressure for a rather loud sound is comparatively small. For a sound of 70 phon pressure is $24 \mathrm{~cm}$. water. For a sound of 77 phon pressure is $30 \mathrm{~cm}$. water.

It does not satisfy us any more to say that the vocal folds function like a "reed instrument."

We can determine that during a sustained tone no change in subglottal pressure takes place. The reclosure of the vocal folds is a muscular effect and not the result of sub-atmospheric pressure.

At another experiment the larynx was instrumentally completely closed off from the tracheal pulmonary system. The patient was also asked to utter $[a:]$ and the following was found:

1. A normal adduction movement of the vocal folds.

2. One vibration lasted a fraction of a second, but no tone was observed except a short rattle.

Films were made of this as well. The vibrations were recorded and corresponded precisely to the previous recording. We can thus prove that the vocal folds can vibrate without air-stream during a certain length of time (our recording was limited to one second).

We can also state the following:

1. A vocal fold, immovably fixed in paramedian position, can vibrate.

2 . The vibrations of the vocal folds are not immediately maximal but are increasing in amplitude (the latter phenomenon being known under the name of "KAISER Effect").

The above experiments were conducted in order to show that the subglottal pressure is not necessary to ensure vibration of the vocal folds, but that the subglottal pressure plays a decisive role for the intensity of a sound and not at all for the pitch.

In a sequel to this article I will discuss...

1. The Chronaxy Measurement of the N. recurrens and its Applications.

2. A New Method to classify singing Voices.

3. A Correlation between Hand Dominance and Disturbances in recurrent Chronaxy in cases of Phonasthenia.

4. I will give a critical discussion of the old and new ideas about Voice Physiology.

5. There will be a Bibliography. 